\title{
ULTRASONOGRAPHIC MEASUREMENT OF PLACENTAL THICKNESS AS A PREDICTOR OF FETAL BIRTH WEIGHT
}

\author{
By \\ Hisham A. Hussein, Ismail M. El-Garhy and Abd El-Monsef A. Sedek \\ Department of Obstetrics and Gynecology, Faculty of Medicine, Al-Azhar University \\ Corresponding author: Hisham A. Hussein;
}

Mobile: 01061106522; E-mail: obshesham@gmail.com

\begin{abstract}
Background: The human placenta develops with the principal function of providing nutrients and oxygen to the fetus.

Objective: to determine the normal sonographically measured placental thickness in millimeters from 18 week onwards and to determine the correlation between measurement and estimated fetal weight.

Patients and methods: This prospective observational study was conducted on 100 pregnant women aged between 18 and 35 years at Obstetrics and Gynecology Department, Edfu General Hospital from October 2018 to January 2020. After Institutional Ethics Committee approval all recruited women were observed for baseline demographic and obstetric data including age, parity and past medical events at first antenatal visit. All women provided an informed written consent and underwent ultrasound evaluation of placental thickness at 18 to 40 weeks of gestation.
\end{abstract}

Results: The mean placental thickness at 2 nd trimester was $24.67 \pm 3.3$ and mean Birth weight $(\mathrm{g})$ was 3044.7 \pm 523.1 with range of (2200-4000).

Conclusion: Placental thickness measured at the level of umbilical cord insertion can be used as an accurate sonographic indicator in the assessment of fetal weight because of its linear correlation.

Keywords: Estimated fetal weight, Placental thickness, umbilical cord insertion, sonographic.

\section{INTRODUCTION}

Normal fetal growth is a critical component of a healthy pregnancy and influences the long-term health of the offspring. Common adult diseases such as type 2 diabetes and cardiovascular conditions have been linked to abnormal fetal growth, particularly fetal growth restriction (FGR). Diagnosis and management are complicated by the use of ambiguous terminology and a lack of uniform diagnostic criteria. Size alone is not an indication of a complication. As a result of this confusion, under intervention and over intervention can occur (Zhang et al., 2016).

Fetal growth and development is one of the most important issues an obstetrician caring for the well-being of the fetus and the mother needs to address. This is because a normally growing fetus with its size within the normal limits means fewer complications during its prenatal and postnatal stages. It also means fewer complications in its infant and childhood stages. In addition, it also 
indicates a potentially healthy, intelligent, and well-grown adult. Any abnormality in fetal growth, whether growth restriction or growth acceleration, is a cause for worry as such abnormalities are usually associated with the risk of prenatal and postnatal morbidity and mortality. Therefore, prenatal diagnosis of these conditions is very important to the physician concerned, because it can help him/her to decide not only the time, but also the mode of delivery. This in turn reduces the risk (Sharma et al., 2016).

Growth is a time-dependent change of bodily dimensions. The human fetus grows at a particularly rapid rate and this is important because a principle of developmental biology is that organisms are more susceptible to injury during periods of fast growth (Tarca et al., 2018).

Birth weight has been used extensively as a parameter to characterize the appropriateness of fetal growth and, to date, remains the most frequently used index to assess size as a proxy to growth. Therefore, in clinical practice, many obstetricians rely on the assessment of sonographic estimation of fetal weight to evaluate fetal size and growth (Milner and Arezina, 2018).

A number of surrogate markers of placental function, including maternal serum analyses and uterine artery Doppler velocimetric indices, have been investigated as early screening tests for these adverse pregnancy outcomes; however, most predictive models including various combinations of surrogate markers have a poor positive predictive value, largely rendering them inadequate standalone screening tests (Salavati et al., 2016).
A correlation between placental weight and fetal birth weight at the time of delivery has long been established. Additionally, pregnancies affected by IUGR and preeclampsia often manifest a placental weight below the 10th percentile for gestational age (Cantonwine et al., 2016). Variations in gross placental morphologic characteristics have also been associated with decreased birth weight and other adverse pregnancy outcomes (Cooley et al., 2013).

The aim of this study was to determine the normal sonographically measured placental thickness in millimeters from 18 week onwards, and to determine the correlation between measurement and the estimated fetal weight.

\section{PATIENTS AND METHODS}

The study had been conducted at Obstetrics and Gynecology Department, Edfu General Hospital.

This was a prospective observational study which included 100 pregnant women from October 2018 to January 2020 .

The study included women with singleton pregnancy, gestational age between 18-40 weeks of gestation, with known last menstrual period and a history of regular menstruation.

Patients with gestational hypertension, diabetes mellitus, Intrauterine growth restriction, hydropes fetalis, congenital malformation, twins, polyhydramnios, last menstrual period not known, irregular menstrual period, abnormal placental and poor visualization of placenta., placental 
with variation in insertion of umbilical cord were excluded.

Written consents were taken from all patients before starting the study with counseling about risk and benefit of study.

Patients were subjected to complete history taking, examination and sonographic technique of placental thickness measurement.

\section{Statistical Analysis:}

Data were collected, coded, entered and analyzed using Microsoft Excel software. Data were then imported into
Statistical Package for the Social Sciences (SPSS version 20.0) software for analysis. According to the type of data, qualitative were represented as number and percentage, quantitative continues group were represented by mean $\pm \mathrm{SD}$, the following tests were used to test differences for significance; Linear regression and ANOVA tests were used followed by Post-hoc test. Correlation by Pearson's correlation or Spearman's. P value was set at $<0.05$ for significant results.

\section{RESULTS}

Mean of Placental thickness 2nd trimester was $24.67 \pm 3.3$ with range of (1832 ), mean of Placental thickness 3nd trimester was $36.83 \pm 7.3$ with range of (2957 ), mean of biparietal diameter 2nd trimester was $60.1 \pm 8.1$ with range of (46.4-70.8), mean of femur length 2nd trimester was $44.5 \pm 6.9$ with range of (32.7-53.8), mean of abdominal circumferance2nd trimester was 199.6 \pm 29.9 with range of (149.1-239), mean of head circumference 2 nd trimester $230.3 \pm 30.1$ with range of (176.8-266.1).
Mean of biparietal diameter 3rd trimester was $82.12 \pm 5.9$ with range of (73.5-90.5), mean of femur length 3rd trimester was $64.1 \pm 5.6$ with range of (56.1-72.3), mean of abdominal circumference 3rd trimester was 287.2 . \pm 26.3 with range of (250326.1 ), mean of head circumference $3 \mathrm{rd}$ trimester 305.3 \pm 20.2 with range of (275.5333.3). Mean Birth weight (g) was $3044.7 \pm 523.1$ with range of (2200-4000) and mean Placental weight was $511 \pm 64$ with range of (290-630) (Table 1). 
HISHAM A. HUSSEIN et al.,

Table (1): Second trimesteric placental thickness, EFW, birth weight, and placental weight

\begin{tabular}{|c|c|}
\hline Variables & \\
\hline \multicolumn{2}{|c|}{ Placental thickness $2^{\text {nd }}$ trimester: } \\
\hline Mean \pm SD & $24.67 \pm 3.3$ \\
\hline Range & $18-32$ \\
\hline $10^{\text {th }}$ percentile & 20.0 \\
\hline $90^{\text {th }}$ percentile & 28.5 \\
\hline \multicolumn{2}{|c|}{ Biparietal diameter $2^{\text {nd }}$ trimester: } \\
\hline Mean \pm SD & $60.1 \pm 8.1$ \\
\hline Range & $46.4-70.8$ \\
\hline \multicolumn{2}{|c|}{ Femur length $2^{\text {nd }}$ trimester: } \\
\hline Mean \pm SD & $44.5 \pm 6.9$ \\
\hline Range & $32.7-53.8$ \\
\hline \multicolumn{2}{|c|}{ Abdominal circumference $2^{\text {nd }}$ trimester: } \\
\hline Mean \pm SD & $199.6 \pm 29.9$ \\
\hline Range & $149.1-239$ \\
\hline \multicolumn{2}{|c|}{ Head circumference $2^{\text {nd }}$ trimester } \\
\hline Mean \pm SD & $230.3 \pm 30.1$ \\
\hline Range & $176.8-266.1$ \\
\hline \multicolumn{2}{|c|}{ Placental thickness 3nd trimester: } \\
\hline Mean \pm SD & $36.83 \pm 7.3$ \\
\hline Range & $29-57$ \\
\hline $10^{\text {th }}$ percentile & 30.0 \\
\hline $90^{\text {th }}$ percentile & 52.0 \\
\hline \multicolumn{2}{|c|}{ Biparietal diameter $3^{\text {nd }}$ trimester: } \\
\hline Mean \pm SD & $82.12 \pm 5.9$ \\
\hline Range & $73.5-90.5$ \\
\hline \multicolumn{2}{|c|}{ Femur length $3^{\text {nd }}$ trimester: } \\
\hline Mean \pm SD & $64.1 \pm 5.6$ \\
\hline Range & $56.1-72.3$ \\
\hline \multicolumn{2}{|c|}{ Abdominal circumference $3^{\text {nd }}$ trimester: } \\
\hline Mean \pm SD & $287.2 . \pm 26.3$ \\
\hline Range & $250-326.1$ \\
\hline \multicolumn{2}{|c|}{ Head circumference $3^{\text {rd }}$ trimester } \\
\hline Mean \pm SD & $305.3 \pm 20.2$ \\
\hline Range & $275.5-333.3$ \\
\hline \multicolumn{2}{|c|}{ Birth weight (g) } \\
\hline Mean \pm SD & $3044.7 \pm 523.1$ \\
\hline Range & $2200-4000$ \\
\hline \multicolumn{2}{|c|}{ Placental weight } \\
\hline Mean \pm SD & $520.36 \pm 52.15$ \\
\hline Range & $290-630$ \\
\hline
\end{tabular}

There was significant relation between placental thickness second trimester and fetal birth weight, also there is high significant relation between placental thickness second trimester and placental weight (Table 2). 
Table (2): Relation between placental thickness second trimester and fetal birth weight and placental weight

\begin{tabular}{|c|c|c|c|c|}
\hline $\begin{array}{l}\text { Placental } \\
\text { thickness }\end{array}$ & $\begin{array}{l}\text { Abnormal thin } \\
\text { placenta less } \\
\text { than } 10^{\text {th }} \\
\text { percentile }(\mathrm{N}=5)\end{array}$ & $\begin{array}{c}\text { Normal } \\
\text { placental } \\
\text { thickness } \\
(\mathrm{N}=44)\end{array}$ & $\begin{array}{c}\text { Abnormal } \\
\text { Increased } \\
\text { thickness of } \\
\text { placenta more } \\
\text { than } 90^{\text {th }} \\
\text { percentile }(\mathrm{N}=5)\end{array}$ & $P$ value \\
\hline \multicolumn{5}{|c|}{ Fetal birth weight (g) } \\
\hline Mean \pm SD & $2751.5 \pm 322.6$ & $3324.1 \pm 377.9$ & $2800 \pm 833.7$ & $<0.003$ \\
\hline \multicolumn{5}{|c|}{ Placental weight $(\mathrm{g})$} \\
\hline Mean \pm SD & $462.2 \pm 49.2$ & $532.3 \pm 37.2$ & $452.5 \pm 102$ & $<0.001$ \\
\hline
\end{tabular}

$\mathrm{F}$ is for ANOVA test.

There was significant relation between placental thickness second trimester and fetal birth weight, also there is significant relation between placental thickness second trimester and placental weight (Table 3).

Table (3): Relation between placental thickness 3rd trimester and fetal birth weight and placental weight

\begin{tabular}{|l|c|c|c|c|}
\hline $\begin{array}{r}\text { Placental } \\
\text { thickness }\end{array}$ & $\begin{array}{c}\text { Abnormal } \\
\text { thin placenta } \\
(\mathbf{N}=\mathbf{3})\end{array}$ & $\begin{array}{c}\text { Normal } \\
\text { placental } \\
\text { thickness } \\
\mathbf{( N = 3 9 )}\end{array}$ & $\begin{array}{c}\text { Abnormal } \\
\text { Increased } \\
\text { thickness of } \\
\text { placenta (N=4) }\end{array}$ & P value \\
Variables & \multicolumn{5}{|l|}{} \\
\hline Fetal birth weight $(\mathbf{g})$ & & $3060 \pm 458$ & $\mathbf{0 . 0 3 2}$ \\
\hline Mean \pm SD & $2751.5 \pm 322.6$ & $3305.2 \pm 361.9$ & & $<\mathbf{0 . 0 1 6}$ \\
\hline Placental weight $(\mathbf{g})$
\end{tabular}

There was significant positive was significant positive correlation between 3rd trimester placental thickness correlation between 2nd trimester placental thickness and fetal birth weight, placental weight and APGAR score. There and fetal birth weight, placental weight and APGAR score (Table 4).

Table (4): Correlation between 2nd and 3rd trimester placental thickness and fetal birth weight, placental weight and APGAR score

\begin{tabular}{|l|c|c|}
\hline Variables & $\mathbf{r}$ & $\mathbf{P}$ \\
\hline fetal birth weight & $\mathbf{0 . 3 5 4}$ & $<\mathbf{0 . 0 5}$ \\
\hline placental weight & 0.332 & $<\mathbf{0 . 0 5}$ \\
\hline APGAR score* & 0.423 & $<\mathbf{0 . 0 5}$ \\
\hline Variables $^{\text {rd }}$ trimester placental thickness & $\mathbf{r}$ & $\mathbf{P}$ \\
\hline fetal birth weight & $\mathbf{0 . 3 1 9}$ & $<\mathbf{0 . 0 5}$ \\
\hline placental weight & $\mathbf{0 . 2 8}$ & $<\mathbf{0 . 0 5}$ \\
\hline APGAR score* & $\mathbf{0 . 4 1 4}$ & $<\mathbf{0 . 0 5}$ \\
\hline
\end{tabular}

$\mathrm{r}$ is correlation coefficient of Pearson's correlation, * is for spearman's correlation 
Changes in fetal weight can be predicted by placental thickness 2nd trimester by $12.5 \%$, also changes in fetal weight can be predicted by placental thickness 3 rd trimester by $10 \%$. Changes in placental weight can be predicted by placental thickness 2 nd trimester by $11 \%$, also changes in fetal weight can be predicted by placental thickness 3rd trimester by $7.8 \%$ (Table 5).

Table (5): Linear regression of placental thickness 2nd trimester and 3rd trimester for prediction of fetal birth weight and placental weight

\begin{tabular}{|l|c|c|c|c|c|}
\hline $\begin{array}{l}\text { Fetal birth weight } \\
\text { Variables }\end{array}$ & B & SE & Beta & Significance & $\mathbf{R}^{\mathbf{2}}$ \\
\hline $\begin{array}{l}\text { placental thickness 2 } \\
\text { trimester }\end{array}$ & 51.1 & 19.5 & 0.354 & $<\mathbf{0 . 0 5}$ & 0.125 \\
\hline $\begin{array}{l}\text { placental thickness 3 } \\
\text { trimester }\end{array}$ & 36.4 & 15.6 & 0.319 & $<\mathbf{0 . 0 5}$ & 0.1 \\
\hline Placental weight & B & SE & Beta & Significance & $\mathbf{R}^{\mathbf{2}}$ \\
\hline $\begin{array}{l}\text { placental thickness 2 } \\
\text { trimester }\end{array}$ & 5.4 & 2.2 & 0.332 & $<\mathbf{0 . 0 5}$ & 0.11 \\
\hline $\begin{array}{l}\text { placental thickness 3 } \\
\text { trimester }\end{array}$ & 3.6 & 1.8 & 0.28 & $<\mathbf{0 . 0 5}$ & 0.078 \\
\hline
\end{tabular}

$\mathrm{B}$, regression coefficient; SE, standard error, R 2 Coefficient of determination

\section{DISCUSSION}

A healthy baby at term is the product of three important factors: a healthy mother, normal genes, and good placental implantation and growth. The placenta is the most important but unfortunately often ignored organ. A normally functioning placenta is required for normal fetal growth and development. It has been historically documented that placental weight in a normal pregnancy at term is about one-fifth of the fetal weight (Nagpal et al., 2018).

Normal placental function and structure are required for normal growth and development of the fetus. Placental thickness is the simplest measurement of placental size and can be measured at any center equipped with ultrasound machine. The correlation of placental thickness with gestational age has been documented by many observers (Quant et al., 2016).
The study was a prospective observational study in 100 pregnant women.

The main results of the study were as following:

Our study show that there mean age is $25 \pm 3.1$ with range of (20-30), mean weight $78 \pm 12$ with range of (55-115), mean height $1.7 \pm 0.07$ with range of (1.55-1.78) and mean BMI is $27.1 \pm 3.7$ with range of 18.8-38.9.

This coped with the study of Nagpal et al. (2018) who studied role of ultrasonographic placental thickness in prediction of fetal outcome and reported that the majority of the women were in age group of 19-23 years. The mean height of women in our study was $154.2 \pm 4.56 \mathrm{~cm}$, and the mean BMI was $21.85 \pm 1.60 \mathrm{~kg} / \mathrm{m}$. Afrakhteh et al. (2013) reported that the age range was 16 to 42 years. 
Similar finding in our study was conducted by Kakumanu et al. (2018) who studied evaluation of placental thickness as an ultrasonographic parameter for estimating gestational age of the fetus in $2^{\text {nd }}$ and $3^{\text {rd }}$ trimesters. They reported that a greater number of patients were in 20-25 years of age $(48.0 \%)$, followed by $26-30$ years $(39.30 \%)$.

Sonographically thick placentae were associated with maternal diabetes mellitus, hypertension, fetal hydrops, and other abnormalities (Balla et al., 2014).

Sersam et al. (2016) reported that maternal parameters were evaluated in the second trimester of the pregnancy, the mean weight was $69.08 \pm 8.11 \mathrm{~kg}$, and the mean body mass index was $26.81 \pm 3.49$ $\mathrm{kg} / \mathrm{m} 2$, with mean BMI gain of $1.15 \pm 0.56$ $\mathrm{kg} / \mathrm{m} 2$, while the mean of placental thickness measured by ultrasound was $2.44 \pm 0.57 \mathrm{~cm}$. The pregnant women were also assessed in the third trimester, the mean weight was $73.05 \pm 7.74 \mathrm{Kg}$, and the mean body mass index was $28.36 \pm 3.42$ $\mathrm{kg} / \mathrm{m} 2$, with mean gain of $2.7 \pm 0.83$ $\mathrm{kg} / \mathrm{m} 2$, while the mean placental thickness measured using ultrasound was $3.58 \pm 0.59$ $\mathrm{cm}$, and mean thickness change between the second and third trimester was 1.14 0.38 .

The present study showed that $46 \%$ of cases had a normal vaginal delivery, and $54 \%$ of cases had cesarean section. This coped with the study of Afrakhteh et al. (2013) who reported that $18 \%$ of mothers had history of previous disease including diabetes, hypertension, thyroid disease and infertility. Two cases of intrauterine fetal demise occurred in the study group. No cases of hydrops fetalis or a specific infectious disease (syphilis, cytomegalovirus infection, toxoplasmosis, schistosomiasis) were reported. The delivery mode was normal vaginal (NVD) in 59\% and cesarean in 41\%. Baby Apgar score of less than 3, 3 to 7 and greater than 7 were observed in $2 \%, 9.3 \%$ and $88.7 \%$ newborns respectively.

Also, this coped with the study of Nagpal et al. (2018) who reported that the mean placental thickness at 32 and 36 weeks were $33.45 \pm 1.62$ and $35.7 \pm 2.08$ mm. In our study, placentae with thickness (determined by antenatal ultrasound) below 10th percentile (Imean 2SD) were considered as abnormally thin placentae. Also placentae with thickness more than $95^{\text {th }}$ percentile ([mean 2SD) were considered as abnormally thick placentae. Placental thickness between $10^{\text {th }}$ and $95^{\text {th }}$ percentile was considered normal at 32 and 36 weeks (The pregnant women were divided according to placental thickness - those with thin, normal and thick placenta.

Nagpal et al. (2018) reported that biometric parameters were $(\mathrm{r}=0.67$ at 32 weeks and $r=0.735$ at 36 weeks). Also, there was a strong positive correlation between placental thickness and birth weight according to Pearson's correlation analysis.

This coped with the study of Afrakhteh et al., (2013) who reported that there was a significant positive correlation between placental thickness and birth weight in the second and third trimesters. However, no correlation was observed with placental thickness change. Placental weight did not correlate with both second and third trimester's placental thickness.

Sersam et al. (2016) reported that a significant positive correlation was found 
between placental thickness and birth weight in the second and third trimesters. Also our results partially agreed with those reported by Balla et al. (2014) who found a linear relation between maternal age and placental thickness, in the second and third trimesters, but disagreed with those reported by Miwa et al. (2014) who noted a lack of relation between placental thickness and maternal age. No relation between placental thickness and gestational age has been documented by Appiah (2018).

A weak positive correlation was observed between placental thickness in the second and third trimesters and birth weight, mainly in birth weight. This was also observed by Afrakhteh et al. (2013). Still, we didn't find a relation between thick placenta and low or high birth weights. This might be explained by small sample size in our study.

This disagreed with the findings by Elchalal et al. (2012), who reported a higher percentage of thick placentas in birth weight at term above $4000 \mathrm{gm}$ or less than $2500 \mathrm{gm}$.

Schwartz et al. (2012) studied twodimensional sonographic placental measurements in singleton pregnancies between 18 and 24 weeks, and found that mean placental thickness and diameter were significantly smaller in small-forgestational-age infants.

There was a significant positive correlation between $2^{\text {nd }}$ trimester placental thickness and fetal birth weight, placental weight and APGAR score

Nagpal et al. (2018) reported that fetal outcome was compromised when placental thickness was $10^{\text {th }}$ percentile
(31.1 mm), with good Apgar scores in $25 \%$ babies and poor Apgar scores in $75 \%$ babies. NICU admissions were there in $75 \%$ cases. Fetal outcome was compromised when placental thickness was $95^{\text {th }}$ percentile at 36 weeks (39.9 $\mathrm{mm}$ ), with good Agar scores in 20\% babies and poor Apgar scores in $80 \%$ babies. All the babies were admitted to NICU.

The present study showed that linear regression of placental thickness in 2nd trimester and $3^{\text {rd }}$ trimester for prediction of placental weight showed that Placental weight can be predicted by placental thickness in $2^{\text {nd }}$ trimester by $11 \%$, and in $3^{\text {rd }}$ trimester by $7.8 \%$. Changes in fetal weight can be predicted by placental thickness $2^{\text {nd }}$ trimester by $12.5 \%$. Also changes in fetal weight can be predicted by placental thickness $3^{\text {rd }}$ trimester by $10 \%$.

Schneider et al. (2010) reported that regression analysis yielded linear mathematical relationships between estimated fetal weight and placental thickness in the second and third trimesters, but the marked variations in fetal weights corresponding to particular placental thickness limit the usefulness of this relationship.

Mathai et al. (2013) noted that regression analysis yielded linear equations of relationship with placental thickness and gestational age in both groups.

Adeyekun et al. (2015) found a mean placental thickness of $22.6 \mathrm{~mm}$ at 15 weeks gestation to $39.2 \mathrm{~mm}$ at 39 weeks. The mean estimated fetal weight ranged from $147.0 \mathrm{~g}$ at 15 weeks to $3187.4 \mathrm{~g}$ at 39 weeks gestation. The correlation and 
probability values were 0.668 and 0.000 respectively.

\section{CONCLUSION}

Placental thickness measured at the level of umbilical cord insertion can be used as an accurate sonographic indicator in the assessment of fetal weight because of its linear correlation.

\section{REFERENCES}

1. Adeyekun, A. A. and Ikubor, J. E. (2015): Relationship between twodimensional ultrasound measurement of placental thickness and estimated fetal weight. Sahel Medical Journal, 18(1): 410.

2. Afrakhteh, M., Moeini, A., Taheri, M. S. and Haghighatkhah, H.R. (2013): Correlation between placental thickness in the second and third trimester and fetal weight. Revista Brasileira de Ginecologia e Obstetrícia, 35(7): 317-322.

3. Appiah PK. (2018): Relationship between the morphology of placenta, Umbilical cord and Perinatal Outcome. Kwame Nkrumah University of Science and Technology.

4. Balla, EAA., Ahmed, MS., Ayad, CE. and Ahmed, AS. (2014): Prediction of fetal growth by measuring the placental thickness using ultrasonography. Journal of Gynecology and Obstetrics, 2:26-31.

5. Cantonwine, D.E., Ferguson, K.K., Mukherjee, B., Chen, Y. H., Smith, N.A., Robinson, J.N., Doubilet, P.M., Meeker, J.D. and McElrath, T.F. (2016): Utilizing longitudinal measures of fetal growth to create a standard method to assess the impacts of maternal disease and environmental exposure. PloS one, 11(1): e0146532.

6. Cooley, SM., Donnelly, JC, Walsh T, McMahon C, Gillan J. and Geary MP.
(2013): The correlation of ultrasonographic placental architecture with placental histology in the low-risk primigravid population. J Perinat Med Mar., 21:1-5.

7. Elchalal, U., Ezra, Y., Levi, Y., Bar-Oz, B., Yanai, N., Intrator, O. and Nadjari, M. (2012): Sonographically thick placenta: a marker for increased perinatal risk-a prospective cross-sectional study. Placenta, 21:268-72.

8. Kakumanu, P.K., Kondragunta, C., Gandra, N. R. and Yepuri, H. (2018): Evaluation of Placental Thickness as an Ultrasonographic Parameter for Estimating Gestational Age of the Fetus in $2^{\text {nd }}$ and $3^{\text {rd }}$ Trimesters. International Journal of Contemporary Medicine Surgery and Radiology, 3(1): 128-32.

9. Mathai, B. M., Singla, S. C., Nittala, P. P., Chakravarti, R. J. and Toppo, J. N. (2013): Placental thickness: its correlation with ultrasonographic gestational age in normal and intrauterine growth-retarded pregnancies in the late second and third trimester. The Journal of Obstetrics and Gynecology of India, 63(4): 230-233.

10.Milner, J. and Arezina, J. (2018): The accuracy of ultrasound estimation of fetal weight in comparison to birth weight: A systematic review. Ultrasound (Leeds, England): 26(1): 32-41.

11.Miwa, I., Sase, M., Torii, M., Sanai, H., Nakamura, Y. and Ueda, K. (2014): A thick placenta: a predictor of adverse pregnancy outcomes. Springer plus, 3(1):14.

12.Nagpal, K., Mittal, P. and Grover, S. B. (2018): Role of Ultrasonographic Placental Thickness in Prediction of Fetal Outcome: A Prospective Indian Study. The Journal of Obstetrics and Gynecology of India, 1-6.

13.Quant, H. S., Sammel, M. D., Parry, S. and Schwartz, N. (2016): Second- 


\section{HISHAM A. HUSSEIN et al.,}

trimester 3-dimensional placental sonography as a predictor of small-forgestational-age birth weight. Journal of Ultrasound in Medicine, 35(8): 16931702.

14.Salavati, N., Sovio, U., Mayo, R. P., Charnock-Jones, D. S. and Smith, G. C. S. (2016): The relationship between human placental morphometry and ultrasonic measurements of utero-placental blood flow and fetal growth. Placenta, 38: 41-48.

15.Schneider, A., Hommel, G. and Blettner, M. (2010): Linear regression analysis: part 14 of a series on evaluation of scientific publications. Deutsches Ärzteblatt International, 107(44): 776.

16.Schwartz N, Wang E and Parry S. (2012): Two-dimensional sonographic placental measurements in the prediction of small for gestational age infants. Ultrasound Obstet Gynaecol, 40(6):674-9.

17.Sersam, L. W., Abdul-Razzak, Z. Z. and Mohammed, S. Y. (2016): Second and Third Trimester Placental Thickness: Correlation with Placental and Birth
Weights. Iraqi Academic Scientific Journal, 15(2): 185-193.

18.Sharma, D., Shastri, S. and Sharma, P. (2016): Intrauterine Growth Restriction: Antenatal and Postnatal Aspects. Clinical medicine insights. Pediatrics, 10: 67-83.

19.Tarca, A. L., Romero, R., Gudicha, D. W., Erez, O., Hernandez-Andrade, E., Yeo, L. and Hassan, S. (2018): A new customized fetal growth standard for African American women: the PRB/ NICHD Detroit study. American Journal of Obstetrics and Gynecology, 218(2): S679S691.

20.Zhang, J., Li, H., Wang, F., Qin, H. and Qin, Q. (2016): Prenatal Diagnosis of Abnormal Invasive Placenta by Ultrasound: Measurement of Highest Peak Systolic Velocity of Subplacental Blood Flow. Ultrasound in medicine and biology, 44(8): 1672-1678. 


\section{قياس سمك المشيمة باستخدام الموجات فوق الصوتية كمؤشر على وزن الجنين}

هشام أحمد علي حسين، إسماعيل محمد طلعت الجارحي، عبد المنصف عبد الحميد

\section{صديق}

قسم أمراض النساء والتوليد، كلية الطب، جامعة الأزهر

E-mail: obshesham@gmail.com

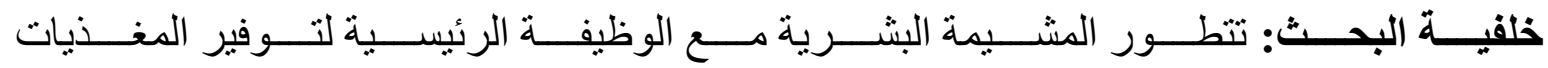

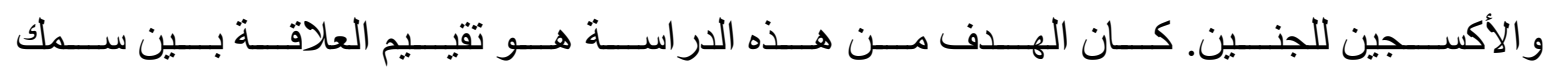
المشيمة مع وزن الجنين المقدر.

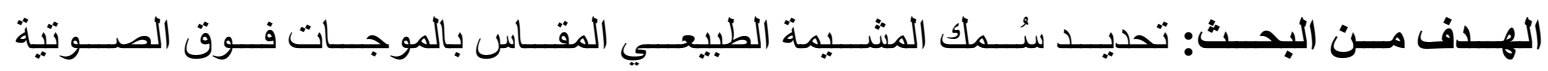

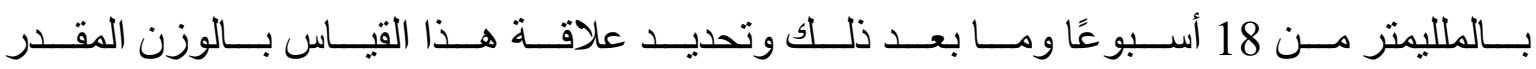
للجنين.

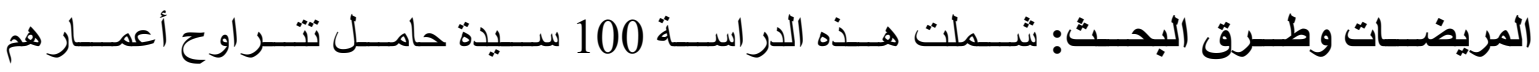

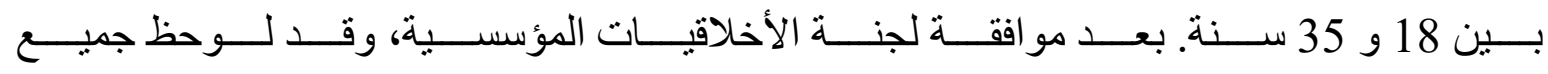

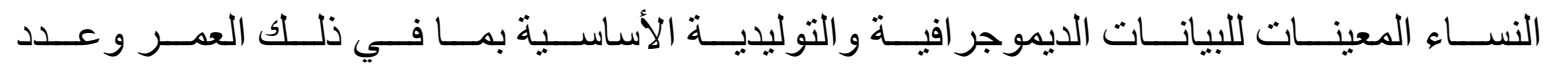

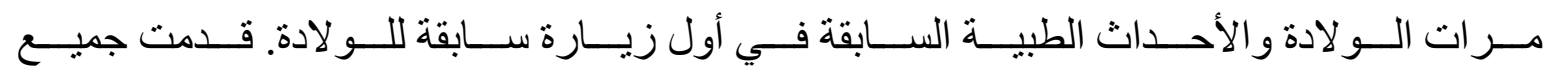

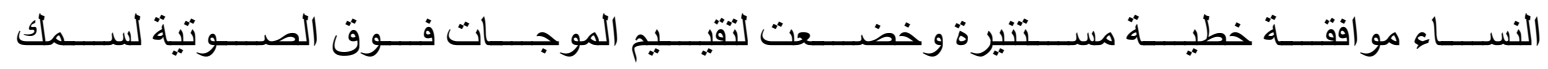
المشيمة في 18 إلى 40 أسبو عًا من الحمل.

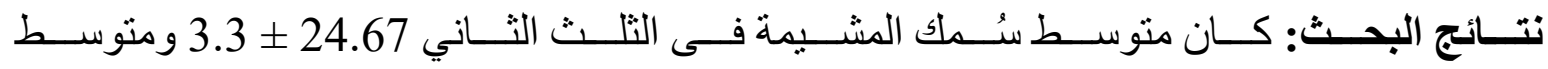
وزن المولود (جم) 3044.7 × 523.1 مع مدى (2200-4000).

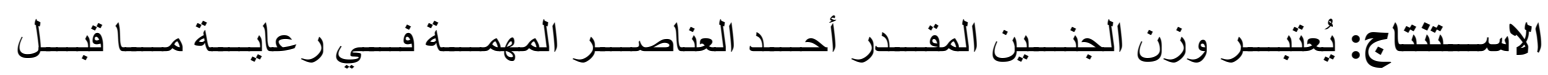

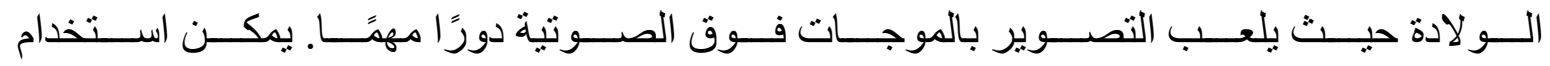

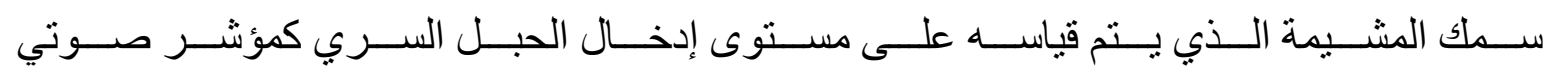
دقيق في تقييم وزن الجنين بسبب ارتباطه الخطي.

الكلمات الدالة : سمك المشيمة - الموجات فو الصوتية - وزن الجنين . 